

Olgu sunumu / Case report

doi: $10.5835 /$ jecm.omu.28.04.012

\title{
Proksimal humerus kırığında internal tespit sonrası subklavikuler bölgeye Kirshner teli migrasyonu
}

\author{
Kirshner wire migration into the subclavicular area after proximal humerus fracture with internal fixation
}

\author{
Murat Korkmaz $^{a^{*}}$, Hayati Öztürk ${ }^{b}$ \\ ${ }^{a}$ Bozok Üniversitesi Tıp Fakültesi Ortopedi ve Travmatoloji Anabilim Dalı, Yozgat \\ ${ }^{b}$ Cumhuriyet Üniversitesi Tip Fakültesi Ortopedi ve Travmatoloji Anabilim Dall, Sivas
}

\begin{tabular}{|c|c|}
\hline MAKALE BİLGILERİ & ÖZET \\
\hline Makale geçmişi & \multirow{4}{*}{$\begin{array}{l}\text { K teliyle tespit özellikle üst ekstremite kırıkları sonrası tespitte sık kullanılır. Deplase ve } \\
\text { unstabil humerus proksimal kırıklarının internal tespitinde kullanılması önerilir. K teliyle } \\
\text { internal fiksasyonda migrasyon telinin başka alana kayması sıktır. Bizim hastamızda } 52 \\
\text { yaşında kadın, hasta sol humerus proksimal uç kırığı nedeni ile } 2 \text { ay önce kırık redüksi- } \\
\text { yon ve K teliyle tespit yapılmış. Röntgen ve CT görüntülerinde telin subklaviküler bölge- } \\
\text { ye migre olduğu izlendi. Tel çıkarıldı. Sonuç olarak hastaların daha sık takip edilmesini, } \\
\text { ameliyat sonu cilt dışında kalan telin bükülmesini öneriyoruz. } \\
\text { J. Exp. Clin. Med., 2011; 28:186-188 }\end{array}$} \\
\hline $20 / 09 / 2010$ & \\
\hline $27 / 11 / 2010$ & \\
\hline $\begin{array}{l}\text { * Yazıșma Adresi: } \\
\text { Murat Korkmaz } \\
\text { Bozok Üniversitesi }\end{array}$ & \\
\hline
\end{tabular}

Tıp Fakültesi Ortopedi ve Travmatoloji

Anabilim Dal1, 66200 Yozgat

E-posta: doktormuratkorkmaz@hotmail.com

\section{ABSTRACT}

$\mathrm{K}$ wires fixation is often used for ostosynthesis particularly in the upper limp. Internal fixation is recommended for displaced and unstable fractures of the proksimal humerus, $\mathrm{K}$ wire internal fixation is potentially complicated by migration of the wire from the

\section{Anahtar Kelimeler:}

Tel

Migrasyon

Proksimal humerus

Kırık

Omuz

Supraklaviküler bölge

\section{Keywords:}

Wire

Migration

Proximal humerus

Fracture

Shoulder

Supraclavicular area fixation site over intime. We report the patient of 52 year old woman who had been operated for left proksimal humerus fracture 2 mounths ago. Roentgenogram and CTscans revealed that the wire migrate to the subclaviculer area. The wire was removed. As a result, patients should be followed closely and suggest to bent to out side part of the wire At the end of operation.

J. Exp. Clin. Med., 2011; 28:186-188

\section{Giriş}

Kırık tespitlerinden sonra pin migrasyonu görülebilmektedir. Özellikle üst ekstremite cerrahisi sonrası pin migrasyonu sık görülür. Pinin migre olduğu vucut bölgesine görede çok değişik komplikasyonlar meydana gelebilir.

\section{Olgu}

Yaklaşık iki ay önce sağ humerus proksimal uç kırığ1 nedeniyle başka bir merkezde opere edilen, sağ kol ve supraklaviküler bölgede ağrı şikayeti olan, elli iki yaşında bayan hasta polikliniğimize başvurdu. Özgeçmişinde 10 yıldır kronik böbrek yetmezliği olduğu, 2 yıldır hemodiyaliz hastası olduğu ve osteoporoz tedavisi aldığı öğrenildi. Yapılan muayenesinde; omuz abduksiyon ve adduksiyonun da ağriya bağl1 kisitlilık, humerus proksimalinde hassasiyet ile cilt altında yabanci cisimle uyumlu, sivri, hareketli lezyon palpe edildi. Direk grafide humerus proksimalinde (Şek. 1) dört adet K teli ile uyumlu radyoopasite görüldü.

Lezyonun anatomik detaylandırılması için doz ayarlaması yap1larak kontrastlı 3 boyutlu bilgisayarlı tomografi yapıldı. K tellerinin 3 tanesinin humerus proksimalinde yerinde olduğu, bir tanesinin migre olarak subklavyan bölgeye, subklavyan venin yaklaşık $1 \mathrm{~cm}$ lateraline kaydığ saptandı (Şek. 2). 


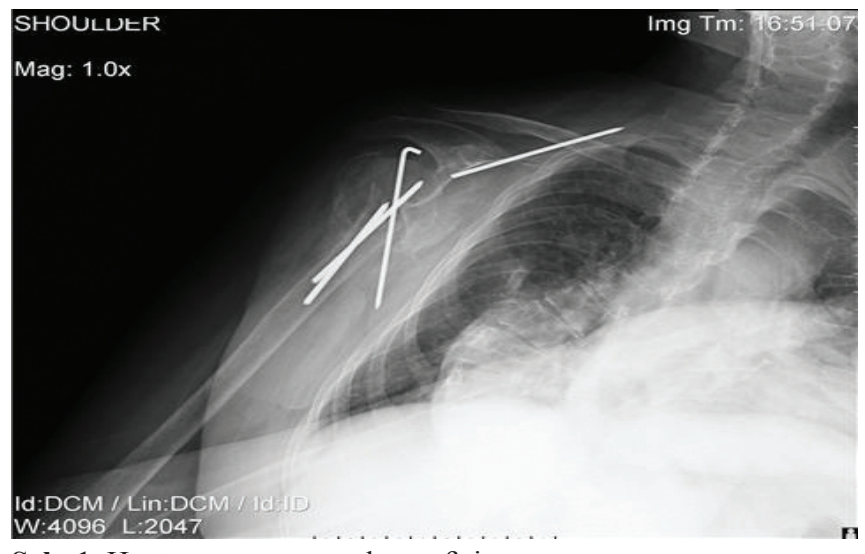

Şek. 1. Hastanın omuz ön arka grafisi

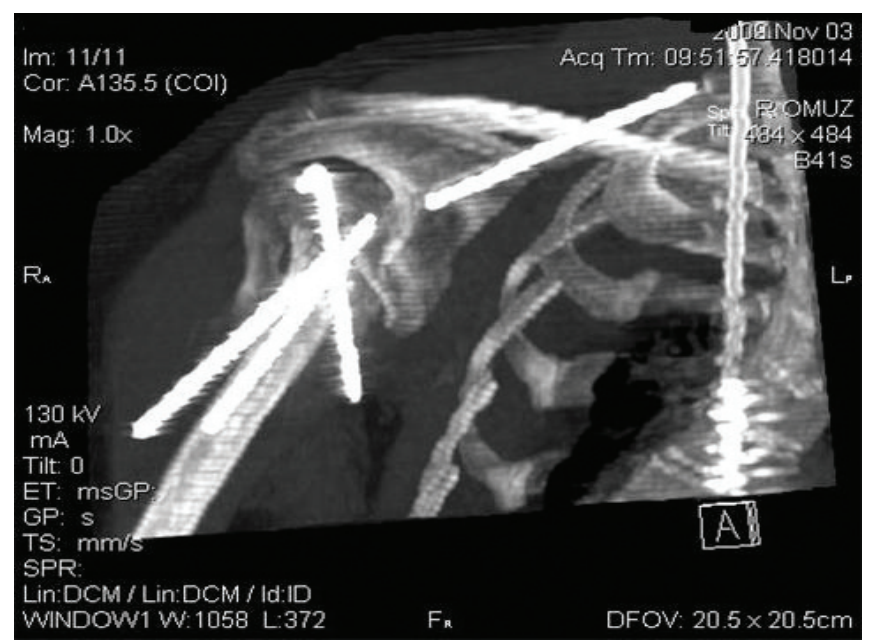

Şek. 2. Hastanın omuz tomografi görüntüsü

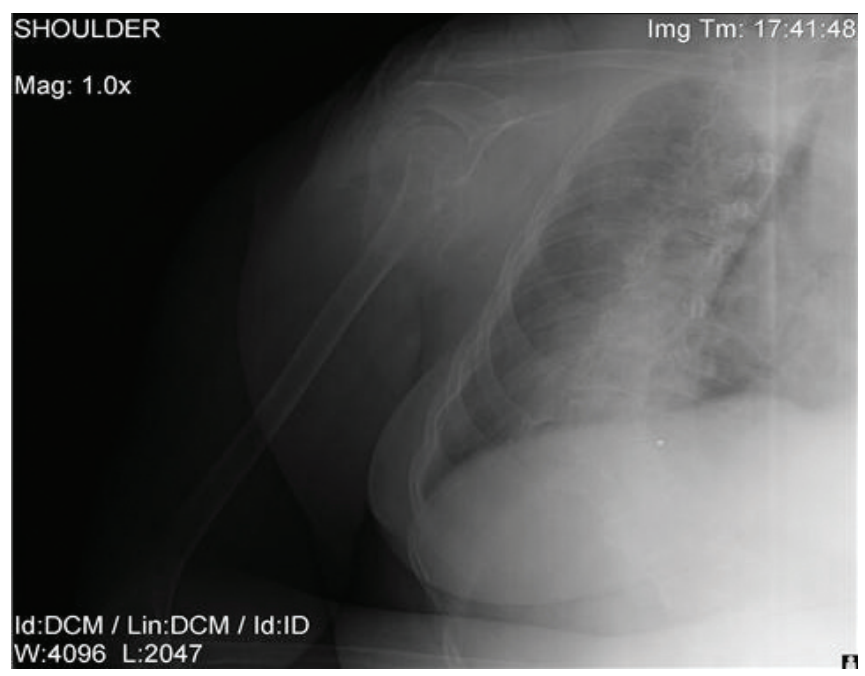

Şek. 3. Hastanın postoperatif omuz ön arka grafisi

Bulgular doğrultusunda; genel anestezi altında lezyon lokalizasyonuna anterior insizyon ile girildi. Pectoralis major ile deltoid kas arasından geçilerek biceps kasının kısa başı ekarte edildi. Skopi yardımı ile migre olan K teline ulaşıldı ve retrograd çıkarıldı. Postoperatif komplikasyon olmayan hasta postoperatif 4. gününde taburcu edildi (Şek. 3).

\section{Tartışma}

Üst ekstremite kırıklarının cerrahisinde $\mathrm{K}$ telleri ile k1rıkların tespit edilmesi kullanılan bir yöntemdir. Özellikle klavikula kırıklarında, akromioklavikular eklem ve sternoklavikular eklem çıkıklarının tespitinde sık kullanılır. $\mathrm{Hu}-$ merus proksimal parçalı kırıklarında da K telleriyle tespit, özelliklede perkutan pinleme sık kullanılan ve iyi sonuçlar alınmaya başlanan bir yöntemdir (Wheeler ve Colville, 1997; Magoveren ve Ramsey, 2008). Genellikle yaşlı ve osteoporotik hastalarda cerrahi tedavi zor ve sonuçları iyi değildir, biyomekanik çalışmalarda tespit yetersizliği görülmektedir (Wheeler ve Colville, 1997; Bogner ve ark., 2008). Bu hastalarda kırıkların K teliyle tespiti sonrası en sık komplikasyon telin başka bir bölgeye migre olmasıdır. Migre olan K teli çok değişik alanlara kayıp oralarda çeşitli komplikasyonlara neden olabilir. Mellado ve arkadaşları (2004), humerus proksimal kırık sonrası $\mathrm{K}$ telinin intratorasik migrasyonu sonucunda hemotoraks tespit etmişlerdir. Hüttl ve arkadaşları (2007), bir vakalarında migre olan teli kalbin apeksinden başarı ile çıkarmışlardır. Yine Freund ve arkadaşları (2007), humerus subkapital kırık sonrası aort ve perikardial yaralanmaya neden olan $\mathrm{K}$ teli migrasyonu sonucu ölüm bildirmişlerdir. Tellerin neden migre olduğu ile ilgili pek çok çalışma yapılmıştır. Mamane ve arkadaşları (2009), ile Sarper ve arkadaşları (2009), migre olan pinlerin dışarıda kalan uçlarının bükülmediğini tespit etmiş, mutlak bükülmesi veya uç kısmı yivli K teli kullanmayı önermiş̧lerdir. Kayalar ve arkadaşları (2009) da osteoporozun migragasyonda etkisine değinerek altmış yaş üzeri osteoporotik kırığı olan hastalarda K teliyle tespitin dikkatli yapılmasını benimsemişlerdir. Tüm önlemlere rağmen Lyons ve Rockwood (1990), operasyondan sonra her dört haftada bir lezyonun yerinin röntgenle takip edilip, gevşeme izlendiği zaman acil olarak K telinin çıkarılmasını belirtmişlerdir.

Bizim vakamızda da başka bir merkezde perkutan pinleme ile humerus proksimal parçalı kırığı redükte edilerek tespit sağlanmıştı. Hastanın takipleri sırasında tespit için kullanılan $\mathrm{K}$ telinin çok nadir bir lokalizasyon olan subklavikuler bölgede olduğu izlendi. Migrasyonun postoperatif tellerin uç kısımlarının bükülmediği, bu duruma yaşa bağlı değişikliklerinde yol açacağ 1 düşünüldü. Migre olan tel damar ve sinir yapılarının olduğu subklavikuler bölgeden acil şartlarda başarıyla çıkartıldı. Hastanın takiplerinde postoperatif damar ve sinir lezyonu gelişmedi.

Sonuç olarak humerus proksimal kırıklarında belirli bir yaş üzerinde, osteoporozda veya osteoporoza neden olabilecek hastalığı olan hastalarda, K teliyle tespit yöntemi en son seçenek olarak düşünülmelidir. Tam olarak migrasyonu önlemese de, K telinin dışarıda kalan ucu mutlaka bükülmelidir. Ameliyat sonu takipler daha sık yapılmalıdır.

\section{KAYNAKLAR}

Bogner, R., Hübner, C., Matis, N., Auffarth, A., Lederer, S., Resch, H., 2008. Proximal humerus in elderly patients J. Bone Joint Surg. Br. 90 , 1602-1607.

Freund, E., Nachman, R., Gips, H., Hiss, J., 2007. Migration of a Kirschner wire used in the fixation of a subcapital humeral fracture, causing cardiac tamponade: Case report and review of literature. Am .J. Forensic Med. Pathol. 28, 155-156. 
Hüttl, T., Kassai, I., Hartyánszky, I., Daróczi, L., Friedrich, O., Széphelyi, K., Szabolcs, Z., 2007. Successful cardiac surgical removal of migrated Kirschner wires used for fixation of the surgical neck of the humerus. Magy Seb. 60, 267-269.

Kayalar, M., Toros, T., Bal, E., Özaksar, K., Gürbüz, Y., Ademoğlu, Y., 2009. Proksimal humerus kırıklarında perkütan tespit için hasta seçiminin önemi. Acta Orthop. Traumatol Turc. 43, 35-41.

Lyons, F.A., Rockwood, CA., 1990. Migration of pins used in operations on the shoulder. J. Bone Joint Surg. Am. 72, $1262-1267$.

Magovern, B., Ramsey, M.L., 2008. Percutaneous fixation of proximal humerus fractures. Orthop. Clin. North Am. 39, 405-416.

Mamane, W., Breitel, D., Lenoir, T., Guigui, P., 2009. Spinal migration of a Kirschner wire after surgery for clavicular nonunion. A case report and review of the literature. Chir. Main. 28, 367-369.

Mellado, J.M., Calmet, J., García, Forcada, I.L., Saurí, A., Giné, J., 2004. Early intrathoracic migration of Kirschner wires used for percutaneous osteosynthesis of a two-part humeral neck fracture: A case report. Emerg. Radiol.11, 49-52.

Sarper, A., Ürgüden, M., Dertsiz, L., Demircan, A., 2009. Intrathoracic migration of Steinman wire. Interactive Cardiovascular and Thoracic Surg. 2, 210-211.

Wheeler, D.L., Colville, MR., 1997. Biomechanical comparison of intramedullary and percutaneous pin fixation for proximal humeral fracture fixation. J. Orthop. Trauma. 11, 363-367. 